\title{
Learning and Teaching Experiences of Sport Education 競技運動教育的學與教經歴
}

\author{
Chung LI Alberto CRUZ \\ Department of Creative Arts and Physical Education \\ The Hong Kong Institute of Education, Hong Kong
}

李宗＼cjkstart高達倫

香港教育學院體藝學系

\begin{abstract}
This paper aims to report a collaborative study project between a teacher training institute and two secondary schools in Hong Kong. It involves the initiation of an innovative curriculum model titled "sport education". The study attached to the practice-referenced and interpretive research perspective with interviewing and video-taping of lessons as tools for data collection. It inquires how 2 experienced PE teachers and 12 secondary 4 students with "high-", "average-" and "low-level" sports skill proficiency articulated their teaching and learning experiences with sport education. The findings revealed that both teachers accepted sport education for providing positive learning experiences for promoting students' generic skills and all round development. Students' active learning, motivation, self initiation, creativity and team cohesiveness were also enhanced. Most students satisfied with experiences of taking roles, performing duties, affiliating with teams, collaborating with others and accomplishing tasks. However, both teachers experienced difficulties of increase in workload. 3 students encountered unpleasant experiences of injury, unfair judgment of the referees and completing assignment after school illustrating their differences in expectation on physical education. Recommendations are made for overcoming these difficulties. The findings of this study provide qualitative insights on how sport education can better be implemented to enhance students' learning in physical education.
\end{abstract}

Keywords: sport education; physical education; curriculum innovation

\section{摘 要}

本文旨在報告一所師資培訓學院與兩所香港中學的一項協作研究計劃, 該計劃涉及推展名為「競技運動教育」創新課程模 式的研究。研究以實踐為本及詮釋理念為依據和利用訪談及課堂錄影為資料搜集工具, 探討了2位資深體育教師和12位運動技能 水平被介定為「高」、「中」及「低」學生對競技運動教育的教與學經歷。研究結果顯示2位體育教師接納此課程模式並提供學 生正面的學習經驗, 促進他/她們的共通能力和全人發展。此模式也能培養學生的主動學習、應激、自我驅動、創意和團隊內聚 力。大部份學生對參與承擔角式、執行職責、加入團隊、與人合作和完成被指派工作等學習經歷也是正面的。但是, 兩位老師均 經歷工作量增加的困難, 其中 3位同學也遇上不愉快的經驗如受傷、不公平的裁判判決和完成家課等。研究結果對推展競技運動 教育以促進學生學習作出建議及質性啓示。

關鍵詞：競技運動教育; 體育; 課程創新 


\section{Introduction}

How teachers and students experience their teaching and learning of a new curriculum has been the interest of physical education (PE) scholars (McCaughtry, Sofo, Rovgno \& Curtner-Smith, 2004; Rovegno, 1998). The central focus relates to how they experience the value of that curriculum. It is assumed that through practicereferenced research, an increased understanding is possible and its "relevance gap" may be filled (Alexander \& Luckman, 2001). This article reports a collaboration project between a teacher training institute and two local secondary schools aiming at putting on trial an innovative curriculum, the sport education (SE). Subsequent to this introduction section, the development of SE and its inclusion in local PE teacher education (TE) are discussed. It follows with the explanation of the methodology of adopting a practice-referenced and interpretive research perspective and the discussion of results. It ends with the conclusion highlighting recommendations of promoting the model in Hong Kong.

\section{Sport Education}

Sport Education (SE) has been regarded as one of the innovative curriculum and instructional models in PE with underlying educational philosophy, intentions, prescribed content, preferred methods and expected learning outcomes (Kinchin, 2006; Metzler, 2005; Siedentop, 2002). According to Siedentop (2002), SE emerges from his doctoral work in the late 1960s and its subsequent promotion in schools. The model has attracted worldwide attention since the publication of his text "Sport Education" in 1994 within which practical units were developed and tested. Since then, there has been considerable amount of studies concerning its impacts on students and teachers in the Western World.

Siedentop (2002) explains, "SE is rooted in play theory, which emphasizes the cultural perspective rather than psychological or instructional perspectives" (p. 414). Accordingly, quality sport experiences rather than effective pedagogical practices are the major focus. Siedentop (2002) further explains that the subject matter of PE could better be explained by reference to play education. Sport should be regarded as "a form of play" which represents an evolution of culture toward a more essential and meaningful form in human affairs (Siedentop, 2002, p. 412). "Sport Education has always been defined as a process through which sport cultures might grow and prosper as humanizing influences in the lives of nations and their citizens" (2002, p. 411). Sports experiences provide contextualized learning for students in $\mathrm{PE}$ for cultivating the sport culture (Siedentop, 1994).

The main goals of SE are to educate students to be players in the fullest sense as competent, literate and enthusiastic sportspeople. Siedentop wrote (2002, p. 411), "I mean competent in the sense that they are knowledgeable games players." Literate sportsperson are those who understand and value sport, and can distinguish between good and bad sport practices. Enthusiastic ones are those who "participate and behave in ways that preserve, protect, and enhance sport cultures".

For achieving these goals, opportunities have to be provided for contextualized learning with a longer teaching unit to develop a sense of affiliation. Record keeping is required for tracking students' performance in the culminating events structured with formal competition within the season. Moreover, efforts have to be taken to produce an atmosphere of festivity in the forms of opening and prize presentation ceremonies. Competitions may be organized in the forms of small-sided and conditioned games with modified rules with students taking a variety of roles and tasks apart from being players such as members of the organizing committee, cheering teams, officials, coaches, captains and so forth (Siedentop, 1994).

In term of pedagogy, teachers are recommended to shift from using more direct and teacher-centered approach to more indirect and student-centered methodologies such as peer coaching, cooperative learning and tasking (Siedentop, 1994). Students are expected to take up increasing amount of responsibility of their learning while shifting the role of the teacher as facilitator gradually. During the process of role taking and tasking, students are more likely to expose in conflict resolution, self and social responsibility, concern and care for others, communication, collaboration and problem solving.

Siedentop (1994), Metzler (2005) and Kinchin (2006) summarized research findings concerning the implementation of SE in the US, UK, Australia and New Zealand. Wallhead and O'Sullivan (2005) also quoted a total of 62 qualitative and quantitative peer-reviewed journal articles concerning various impacts of SE on students and 
teachers. Studies had involved students of the elementary (Bell, 1998; Mowling, Block \& Hastie, 2006), middle (Mohr, Townsend \& Pritchard, 2006), high school (Carlson \& Hastie, 1997) and undergraduate levels (Collier, 1988; Curtner-Smith \& Sofo, 2004; McMahon \& MacPhail, 2007; McCaughtry, Sofo, Rovgno \& Curtner-Smith, 2004) as well as serving PE teachers (Alexander \& Luckman, 2001). Inquiries had also been placed on high-skilled (Kinchin, 2001), low-skilled (Carlson, 1995) and at risk students (Hastie \& Sharpe, 1999).

Inquiring issues including instructional strategies (Kinchin, 2001) and application of SE to different sports activities like soccer, lifetime leisure activities and rugby (Brown, Carlson \& Hastie, 2004; Mohr et al, 2006; Mowling, Block and Hastie, 2006) were conducted. Other researchers concentrate their studies on evaluating various dimensions of student learning like preference of PE (Alexander, Taggart \& Thorpe, 1996; Carlson \& Hastie 1997; Kinchin, 2001), engagement and levels of effort have also been reported (Carlson \& Hastie 1997). Others confirm that educational contributions of SE on students' motor skill development (Alexander et, al 1996; Carlson, 1995), fitness, personal and social development (Alexander \& Luckman, 2001), values in terms of affinity, equity, culture and social system (Siedentop, 1998). They provide strong and persuasive evidence that SE can enhance students to become literate, enthusiastic and competent sportspersons.

However, findings of male domination during competition and inequitable opportunities for some nonplaying roles were reported on girls (Hastie, 1998). Kirk and Kinchin (2003) also quoted that some urban pupils refused to take up responsibility and the direction of others. They raised that "among many potential lines of research we still have much to learn about why SE do not work in some settings and what might be some additional difficulties which emerge during implementation" (p. 228). How SE might be interpreted and responded by teachers and students in Hong Kong is relatively unknown. As a matter of fact, it has yet to become a topic of local discussion and curricular feature.

\section{Promotion of Sport Education in Hong Kong}

The idea of introducing SE in the PETE curriculum at the Hong Kong Institute of Education was launched for the Advanced Teacher Certificate in Education programme (ACTE) for in-service PE teachers as early as 1997. The initiation envisages the idea of making use of PETE as the "change agent" for local PE curriculum development and improvement. SE has later been incorporated in the pre-service Bachelor of Education (BEd) PETE programme. Its inclusion serves as one of the measures in response to the current education reform as both of them stress on constructivist pedagogy with emphases on student-centered learning.

A few local research projects concerning putting on trial the SE have been launched: Lam and Li (2006) compared students' perceived learning outcomes of the soccer teaching unit conducted in the forms of Command style and SE. Data of two classes of 76 Secondary 4 (S4) female students were collected through focus group interview. The results indicated that students involving in SE expressed more positive attitude and motivation for attending PE, performed better in the social skills and exhibited more initiative and autonomy in participating in and out of class activities when compared with the group involved in PE lessons conducted in the form of the Command style. The soccer league, team affiliation, festivity, decision making and role taking were elements perceived by students as motivating measures.

Leung and $\mathrm{Li}$ (2007) studied the task and ego orientations of $24 \mathrm{~S} 7$ students after participating in 8 double-lesson football unit conduced in the form of SE. With the questionnaire technique, they found that SE was capable of facilitating students' task orientation, improving their motive for PE lessons and becoming more active and positive towards their learning. Both studies suggested to promote SE as one of the alternatives for PE curriculum in Hong Kong.

This study aimed to supplement local research information by inquiring teachers' and students' experiences on SE. It highlighted possibly the use of research to see the effectiveness of an innovative curriculum with reference to students' and teachers' learning and teaching. 


\section{Methodology}

The study adopted the practice-referenced orientation aiming to inquire how 2 serving $\mathrm{PE}$ teachers and their S4 students experienced teaching and learning of SE teaching units. It was primarily qualitative and the interpretive inquiry perspective was adopted to capture their experiences holistically and naturalistically. The "hermeneutics" is stressed illustrating the importance of understanding and interpretation of how they gave meanings to their teaching and learning experiences with the awareness of the context (Bleicher, 1982).

\section{Data Collection and the Participants}

Data were collected through semi-structured interviews at the end of their SE units. The timing was thought to be versatile and practical. Each interview lasted for about 15 minutes. The duration was regarded suitable for collecting necessary information and maintaining students' concentration. Interviewing questions including their knowledge, perceptions and experiences of teaching and learning were structured.

The 2 teachers ( 1 male and 1 female with the pseudonyms of $\mathrm{M}$ and $\mathrm{L}$ respectively) were purposefully selected because of their dedication and willing to take initiatives in developing quality PE curricula in their schools. A stratified sample of 12 students (6 male and 6 female) with 4 each in the "high", "average" and "low" skill proficiency level assigned by the teachers involved in this study. They were in an average age of 16 and were thought to be mature enough to spell out their SE experiences. The sample of the "high level" of skill proficiency included 2 students from each school with the pseudonyms of $\mathrm{H} 1, \mathrm{H} 2, \mathrm{H} 3$ and H4. They had represented their schools in the inter-school competition for handball or basketball. Those "average level" students with the pseudonyms of M1, M2, M3 and M4 were those who had participated in the inter-house handball or basketball competition. The group identified as the "low level" included students L1, L2, L3 and L4 who had not participated in any sports competition in schools.

The second source of data included video-taping of each lesson. They provided authentic and contextual information on how teachers and students actually involved in the lessons.

\section{The SE teaching units}

2 teaching units including basketball and handball were planned and taught by $\mathrm{M}$ and $\mathrm{L}$ respectively with the consultation of researchers. They were structured and implemented with elements of affiliation, record keeping, culminating events, season, formal competition and festivity (Seidentop, 2002). Basketball and handball were selected because they were popular and common teaching content for local secondary schools. Most PE teachers were competent to teach these activities and respective facilities were available.

\section{Data Analysis}

All data were transcribed, coded and organized inductively. Emerging and recurring themes concerning teachers' and students' teaching and learning experiences in SE were decontextualized with content analysis and constant comparison suggested by Strauss and Corbin (1998). Phenomena such as their knowledge, experiences, difficulty and values perceived while involving in SE were interpreted in a wider context of their teaching and learning. They were then interpolated with the data and cross-case analysis in the process of "saturate", "abstract", "conceptualize" and "test" with a spiral and back and forth manner.

"Trustworthiness" and "authenticity" of the data were employed to establish the credibility and legitimacy of this research. During the negotiating access, participants' consent was obtained. They were explained with the details of the study, their rights and obligations. Interviews were translated and direct quotations with students' and teachers' own wordings were extracted to ensure the authenticity of the data. Data of the video taping of the lessons were used for triangulating the interviewing accounts. It was hoped to de-contextualize the complexities of their SE experiences in full.

\section{Discussion of the Results}

\section{Biographical Information of the Teachers}

$\mathrm{M}$ was a dedicated and experienced male teacher with 16 years of PE teaching. After obtaining his teacher's certificate, he went on attaining his BEd and MEd degrees in local universities. He came to know SE through discussing and sharing with the researchers. $\mathrm{L}$ was an enthusiastic and innovative female PE teacher 
with 11 years of PE teaching. She possessed a BEd and was now enrolling in her MEd degree. She knew SE while attending the ACTE and BEd programmes. She had tried the model in her PE programme. They taught basketball and handball teaching units for their S4 students respectively. Their biographical details were summarized in Table 1 for reference.

Table 1. Biographical information of the teachers.

\begin{tabular}{|l|l|l|}
\hline Participants & $\begin{array}{l}\text { Secondary School Male } \\
\text { PE Teacher (M) }\end{array}$ & $\begin{array}{l}\text { Secondary School Female } \\
\text { PE Teacher (L) }\end{array}$ \\
\hline Teaching Experience & 16 Yrs & 11 Yrs \\
\hline Academic Qualification & MEd & BEd \\
\hline Knowledge of SE & Before the research project & ACTE; BEd. \\
\hline No. of Lessons in SE & 5 double lessons & 6 double lessons \\
\hline Areas of teaching & Basketball & Handball \\
\hline Class taught & S4 Boys & S4 Girls \\
\hline
\end{tabular}

From the analysis of the video-taped lessons, both teachers adopted relatively short teaching units of 5 and 6 double lessons respectively in accordance with their scheduled yearly planning. It was observed that both teachers tried hard to implement SE through planning thoroughly, assigning tasks to students in detail and guiding them even after class. Most students engaged fully in the lessons. They were interested and involved in activities like skill practices, game-play, roles taking and tasks accomplishment.

Both teachers conducted their PE lessons systematically with class routine of warming up activities, skills development and practices, games for application and concluding activities. They adopted the direct teaching approach for introducing the skills and tactics at the first half of the unit and allowed their students to involve in organizing the tournament in the last two lessons. They formed teams with mixed ability for their students at the first lesson. Students from each team were assigned to perform and prepare different roles like organizing committee, officials, coaches, first aiders and team captains. All teams were required to search for information, finalize plans and submit "paper work" such as drafting of the rules and regulations for the tournament, officiating techniques, coaching ethics, practice drills, and skills and equipment in first aid during their spare time. Extra-tutorial sessions with individual groups were organized after school. The teachers also set deadlines for each group to submit their assigned tasks.
$\mathrm{M}$ incorporated the physical fitness training routine of running around the school campus and performing standardized calisthenic exercises at the first part of each lesson. He also arranged coaching sessions for students to practise their coaching plans during the third and fourth sessions. On the other hand, L allowed her students to name their teams, dress their team uniform during the formal competition, and publicize their tournament in the notice board and school TV.

Through inductive analysis and constant comparison of the interviewing scripts, the following 5 themes concerning how teachers and students experienced their basketball and handball units conducted in the form of SE emerged:

\section{Theme 1 - Educational Values of SE Perceived by the Teachers}

Both teachers commended highly on the positive values that their students experienced from SE. M claimed that his students enriched in social development and generic skills like communication and cooperation. In the interview, he commented:

The major characteristic of SE was to train students' team spirits through which social objectives like collaboration and communication skills were achieved....All students participated fully through taking different roles and their individual needs were catered... The experience benefited their organizing and managerial abilities...it could also train up their thinking skill like how to organize a successful competition and how to train up team members... (M) 
M related particularly his students' learning concerning role taking experiences. $\mathrm{He}$ observed that those students involved in the organizing committee learnt how to organize a tournament and became familiar with the competition systems. For those serving as coaches, they gained the experience of giving clear instruction and demonstration. The referee group was found more familiar with the rules of the game and was more aware of the importance giving clear and decisive judgment while officiate the games. All his students experienced the importance of communication, respect others, team affiliation and spirit.

$\mathrm{L}$ also observed a wider scope of contributions $\mathrm{SE}$ for her students. The contributions included cognitive development such as promoting higher order thinking skill and psychomotor enrichment like improving handball skills. She related the emotional development and the carry over values of SE on her students. She claimed that her students' wining and losing experiences could be transferred to manage the examination results. In the interview, L expressed eagerly:

SE is worth to be promoted as it could cultivate students' emotional stability, higher order thinking and communicative abilities. They experienced more winning and losing experiences. Such experiences helped facilitating their management of daily life such as dealing with challenges in examinations. It also enhanced students' cognitive understanding and skills of handball, and affective development. This enabled them to develop fully. $(L)$

She also claimed that her students had fun. All her students experienced the importance of "division of labour". In her mind, her students put much effort concerning "taking roles", "performing duties" and "organizing tournament". She was satisfied with her students' "team spirit" and "caring for others".

In congruence with the findings of similar studies conducted in the Western world (Siedentop, 1998; Sinelnikov \& Hastie, 2008) and locally (Lam \& Li, 2006), the teachers commended highly the positive learning of SE that their students' had experienced. They observed that their students had tried their best to take up roles, work with others and accomplish their assigned duties. Other educational values included enrichment in communication and collaboration skills. On the whole, SE experience could enhance students' all-round development.

\section{Theme 2 - Comparison with Previous Mode of PE Teaching}

Both teachers tended to compare SE with their traditional mode of teaching. They both valued SE for more capable of motivating students for PE class, enhancing active learning, contributing to team cohesiveness and catering for diversity. In the interview, $\mathrm{M}$ recalled how his students took up their initiative in learning:

Students were interested more in my PE lessons. They organized training by themselves. They demonstrated more team spirit...They liked to attend PE classes and asked more questions about their roles to be taken and my instruction...It was surprising to see low skilled students could experience their importance... Skilled students could also benefit by taking care of the weaker ones...These could not be achieved through traditional mode of teaching as the lesson was dominated by teachers' direct instruction. (M)

L supported by saying that:

My students liked the lessons to be conducted in the form of SE. Different groups actively searched information from the web concerning tournament organization, officiating, first aid treatment, coaching and practising drills. I also saw them organizing training sessions during lunch time and after school. They composed their promotion strategies, dressed their team uniform and named their teams with unexpected creativity. It was fantastic. (L)

It appears that SE has been accepted by both teachers. For them, SE experiences are more capable of promoting students' active learning, motivation, self initiation, creativity and team cohesiveness which seldom occur in the lessons being conducted in the form of the traditional mode. The findings echo some of the studies conducted by Alexander, Taggart and Medland (1993); Hastie (1996); Carlson and Hastie (1997); and Leung and Li (2007) within which SE was found more capable of increasing students' initiation, motivation, engagement and effort. 


\section{Theme 3 - Difficulties encountered}

Both teachers expressed that extra efforts and commitment for preparing lessons, supporting students in searching information and holding meetings with students after class were required for implementing SE. Moreover, $\mathrm{L}$ also highlighted the issue of assessment for students' performance when the SE was adopted. The following table summarized articulations between the 2 teachers on the difficulties encountered:

Table 2. Comparison of Teachers' Articulations on Difficulties for Implementing the SE.

\begin{tabular}{|l|l|}
\hline $\mathrm{M}$ & $\mathrm{L}$ \\
\hline More time \& effort & More time commitment \\
\hline Preparation of notes & Difficulty in Assessment \\
\hline Helping students to search for information & Helping students' to search for information \\
\hline Contacting students through meetings and emails & Holding meetings with students after school \\
\hline Monitoring students' progress & \\
\hline
\end{tabular}

Both teachers were dedicated and committed to support students in preparing and accomplishing the assigned tasks like organizing meetings, searching information, preparing notes and monitoring their progress. Supporting teachers in preparing their lessons, compiling websites information for organizing tournament, officiating and coaching, and compiling hints for effective handling of meetings appear to be helpful for teachers to implement SE.

\section{Theme 4 - Students' Experience of SE}

Regardless of their levels of skill proficiency, most students expressed satisfactory remarks on their SE experiences. Their remarks included "very happy", "very good", "challenging", "happy", "good" and "OK". They also articulated their SE experiences with complementary descriptions like "more participation", "something new", "worthwhile to be promoted", "could not have been better" and "could have been longer".

Most students experienced some forms of positive learning experiences like taking up roles and duties. They claimed that they had learnt how to organizing tournament and team practices. They were more aware of the importance of collaboration and team spirit, to be serious and dedication. Such experiences made them understand more about the sport culture.
Most students expressed that they liked PE lessons conducted in the form of SE. They articulated the reasons with "more personal involvement in competition", "could apply what they had learnt in the lesson", "could serve as referee and coach etc. apart from serving as players", "could train with teammates", "could learn referee's hand signals' and "could organize tournament". Other satisfying experiences included "participating in competition", "taking roles and fulfilling duties", "exhibiting seriousness and dedication", "demonstrating team spirit", "scoring and winning" and "more participation from classmates".

Taking up roles and accomplishing tasks assigned appear to be satisfying experiences for most students. Their complementary remarks on their satisfying experiences of SE map well with that of the teachers' comments. Grant, Trendinnick and Hodge (1992) and Alexander et al (1993) conducted their studies in New Zealand and Australia respectively concerning students' perceptions on SE. They revealed that students commented positively on their SE experiences. Interestingly, most students in this study not only satisfied with SE experience but also began to appreciate the work of their PE teachers.

\section{Theme 5 - Students' Dissatisfying Experiences}

3 students (H1, M2 and L4) joined the SE with diverse capabilities and expectations. They encountered unpleasant learning experiences. As the result, they expressed that they preferred their PE lessons to be conducted in the form the previous mode. 
H1 was a tall, sporty and academically-inclined student. He was one of the key members of the school basketball team. His dissatisfying experiences concerned "being injured"; "being forced to submit assignment like coaching plan which caused him time after school" ; "coaching others and teammates who were unable to perform with expectation" and "taking up only one role with limited learning".

M2 was a tall, well-built male student. $\mathrm{He}$ had participated in the inter-house basketball competition since S1. He claimed that nothing had been learnt. In the interview, he complained, "it was just like playing games as usual". He was disappointed with referees' decisions and unfair judgment which caused the defeat of his team in the competition. The poor performance of the referees made him think that the tournament was unfair. $\mathrm{He}$ did not like the assignment of collecting information and drafting rules and regulations for the tournament after school.

L4 was a hardworking and academically-inclined female student. She looked a bit weak physically. She criticized that she was "fouled by others" and the "paper work" assignment caused her much time for organizing the tournament and left her little time to concentrate on her study. For her, PE should be activity oriented and she did not expect being assigned with PE homework.

The unpleasant experiences encountered by H1, M2 and L4 may illustrate different expectations of students on PE. H1 was frustrated with his classmates' performance during practices under his coaching. M2 was unhappy with the referee's decision during the competition. L4 claimed that she was fouled by others during the game. H1 expected that submission of coaching plans caused him extra time and burden. M2 was also unhappy of doing extra work of organizing competition after class. L4 did not expect to do extra work apart from involving in some physical activities during class. All 3 of them did not expect to be assigned with PE home work. Their dissatisfaction illustrates that better provision, support, monitoring and explanation from teachers concerning the implementation of SE were required.

\section{Conclusion and Recommendation}

Both teachers commended highly on the contribution of SE for providing positive learning experiences for their students. Through role taking and tasks accomplishing, their students were enriched in handball and basketball skills and understanding, and all-round development. Students' knowledge and skills of organizing tournament, officiating and team affiliation had been promoted. SE was more capable of enhancing students' active learning, motivation, self initiation, creativity, team cohesiveness, engagement and effort. They preferred SE when compared with their traditional mode of PE teaching.

Students also experienced satisfying learning experiences like taking roles, performing duties, team affiliation, dedicated involvement and competition through participating in SE. The findings illustrate that SE can work well even for teaching units with shorter duration (5-6 double lessons) in the case of Hong Kong.

For implementing the SE, both teachers related their difficulties with extra-commitment such as out-of-class efforts for supporting students in organizing meetings, searching information, preparing notes, monitoring progress and assessment. Supporting teachers in preparing their lessons, compiling websites information for organizing tournament, officiating and coaching information, and hints for effective handling of meetings appear to be helpful for teachers to implement SE.

3 students had unpleasant learning experiences of SE because of being injured, fouled by others, doing homework and difficulty of training up teammates. The findings convey conceptual and pedagogical implications for teachers. Changing students' conception concerning PE is only physical activity and after class assignment should not be part of it have to be initiated. Moreover, closer monitoring of all activities and provision of timely feedbacks to students' performance during classes may be necessary. Moreover, post unit sharing and debriefing may help students to reflect their experiences critically. At the same time, conflicts and mismatches of students' experiences and conceptions on SE as well as PE should be resolved. 
Together with a number of previous local studies and similar research on teachers and students in the Western World, the findings of this study appear to provide encouraging and supplementary information supporting the feasibility of the inclusion of SE as an alternative curriculum model in the local PE.

Through the collaboration between a teacher training institute and 2 schools, this study illustrates an innovative curriculum model can be initiated and put on trail through practice-referenced type of research. Teachers can develop and establish themselves with identities and roles as both the researchers and practitioners. With the research evidence, the feasibility of a curricular initiative is demonstrated and the basis for improving quality $\mathrm{PE}$ provisions is also established for enhancing students' learning. Aligned with such type of action research, this partnership initiative provides successful collective commitment to professional learning for both teachers and the researchers.

Following this study, replication is worthwhile to be conducted in other schools as it is interesting to determine whether SE can initiate similar positive teaching and learning experiences for teachers and students with different contexts.

\section{References}

Alexander, K., \& Luckman, J. (2001). Australian teachers' perceptions and uses of sport education curriculum model. European Physical Education Review, 7(3), 243-267.

Alexander, K., Taggart, A., \& Medland, A. (1993). Sport education in physical education: Try before you buy. Australian Council for Health, Physical Education, and Recreation Journal, 40(4), 16-23.

Alexander, K., Taggart, A., \& Thorpe, S. T. (1996) A spring in their steps? Possibilities for professional renewal through sport education in Australian schools. Sport, Education and Society, 1(1), 23-46.

Bell, C. (1998). Sport education in elementary school. Journal of Physical Education, Recreation and Dance, 69(5), 36-39.
Bleicher, J. (1982). The Hermeneutic imagination. London: Routledge

Brown, T. P. J., Carlson, F. B., \& Hastie, P. A. (2004). A comparison of rugby seasons presented in traditional and sport education formats. European Physical Education Review, 10(2), 199-214.

Carlson, T. B. (1995). "Now I think I can": The reaction of eight low-skilled students to sport education. Australian Council for Health, Physical Education and Recreation Healthy Lifestyles Journal, 42(4), 6-8.

Carlson, T. B., \& Hastie, P.A. (1997). The student social system within sport education. Journal of Teaching in Physical Education, 16(2), 467-477.

Collier, C. (1988). Sport education and pre-service education. Journal of Physical Education, Recreation and Dance, 69(5), 44-45.

Curtner-Smith, M. D., \& Sofo, S. (2004). Pre-service teachers' conceptions of teaching with sport education and multi-activity units. Sport, Education and Society, 9(3), 347-377.

Grant, B. C., Trendinnick, P., \& Hodge, K. (1992). Sport education in physical education, New Zealand Journal of Health, Physical Education and Recreation, 25(3), 3-6.

Hastie, P. (1998). The participation and perception of girls during a unit of sport education. Journal of Teaching in Physical Education, 17(2), 157-171.

Hastie, P., \& Sharpe, T. (1999). Effects of a sport education curriculum on the positive social behaviour of at-risk rural adolescent boys. Journal of Education for Students Placed at Risk, 4(4), 417-430.

Kinchin, G. D. (2001). A high skilled pupil's experiences with sport education. ACHPER Healthy Lifestyles Journal, 48(3-4), 5-9.

Kinchin, G. D. (2006). Sport education: A view of the research. In D. Kirk, D. Macdonald and M. O'Sullivan, (Eds.), The handbook of physical education (pp. 596609). Thousand Oaks, California: Sage. 
Kirk, D., \& Kinchin, G. (2003). Situated learning as a theoretical framework for sport education. European Physical Education Review, 9(3), 221-235.

Lam, C. K., \& Li, C. (2005, July). Introduction of the school based curriculum-The implementation of sport education model. Paper presented at the Summer School Conference for PE teachers, Hong Kong.

Leung, K.Y., \& Li, C. (2007, June). Theory and Practice of Sports Education Model - An experience from SPHRC Kung Yik She Secondary School. Paper presented at the Summer School Conference for PE teachers, Hong Kong.

McCaughtry, N., Sofo, S., Rovegno, I., \& CurtnerSmith, M. (2004). Learning to teach sport education: Misunderstandings, pedagogical difficulties and resistance. European Physical Education Review, 10(2), 135-155.

McMahon, E., \& MacPhail, A. (2007). Learning to teach sport education: The experiences of a pre-service teacher. European Physical Education Review, 13(2), 229-246.

Metzler, M. W. (2005). Instructional models for physical education ( $2^{\text {nd }}$ ed.). Scottsdale. AZ: Holcomb Hathaway.

Mohr, D. J., Townsend, J. S., \& Pritchard, T. (2006). Rethinking middle school physical education: Combining lifetime leisure activities and sport education to encourage physical activity. Physical Educator, 63(1), 18-29.

Mowling, C.M., Block, S. J., \& Hastie, P.A. (2006). Fourth grade students' drawing interpretations of a sport education soccer unit. Journal of Teaching in Physical Education, 25(1), 9-35.

Rovegno, I. (1998). The development of in-service teachers' knowledge of a constructivist approach to physical education: Teaching beyond activities. Research Quarterly for Exercise and Sport, 69(2), 147-162.
Siedentop, D. (1994). Sport education. Champaign, IL: Human Kinetics.

Siedentop, D. (1998). What is sport education and how does it work? Journal of Physical Education, Recreation and Dance, 69(4), 18-20.

Siedentop, D. (2002). Sport education: a retrospective. Journal of Teaching in Physical Education, 21(4), 409-418

Sinelnikov, O., \& Hastie, P. (2008). Teaching sport education to Russian students: An ecological analysis. European Physical Education Review, 14(2), 203-222.

Strauss, A. L., \& Corbin, J. (1998) Basics of Qualitative Research: Techniques and procedures for developing Grounded Theory. United States of America: Sage.

Wallhead, T., \& O'Sullivan, M. (2005). Sport education: Physical education for the new millennium. Physical Education and Sport Pedagogy, 10(2), 181-210.

\section{Acknowledgement}

The study was supported by the small scale departmental research grant of the Department of Creative Arts and Physical Education, The Hong Kong Institute of Education.

\section{Correspondence}

Chung Li, PhD.

Department of Creative Arts and Physical Education The Hong Kong Institute of Education, Hong Kong 10 Lo Ping Road,

Tai Po, NT, Hong Kong

Telephone : (852) 9274 0770;

Fax $\quad$ : (852) 29487848

Email : cli@ied.edu.hk ; acruz@ied.edu.hk

Alberto Cruz, EdD.

Department of Creative Arts and Physical Education The Hong Kong Institute of Education, Hong Kong Phone : (852) 29487847

Fax : (852) 29487848

Email : acruz@ied.edu.hk 